\title{
New design of floor beams for low-rise construction
}

\author{
Natalia Vorontsova ${ }^{1}$, Andrey Makarevich ${ }^{1}$, and Natalia Stoyushko ${ }^{1, *}$ \\ ${ }^{1}$ Far Eastern Federal University, 20, Ajax St.,Vladivostok, Russky Island, 690000, Russia
}

\begin{abstract}
We are reviewing one of the part of solution to problem of providing residential property for population. Construction price can be reduced due to the use of glued plywood floor beams. To simplify production technique and to reduce its price it has been offered to eliminate splicing of plywood walls and to apply beams with perforated walls. Stress-strain analysis and comparison of different design models behavior were made with photo elasticity method. Models of the optically-responsive material put in the strain viewer area and loaded with designed forces, allowed to observe real stress patterns. Models' state of strain was evaluated with dial gauge.
\end{abstract}

\section{Introduction}

The problem of available low-rise residential property for citizens is quite important. One of the ways to solve this problem is low-rise construction where precast and cast-in-place concrete slabs of different design concepts as well as floors on steel and wooden beams can be used for flooring. The use of glued plywood universal beams is the most cost-efficient technique, because in this solution the material is distributed throughout the full height of section [1].

Glued plywood beams have been used in floor structures for buildings of different purposes since 1930s. During their fabrication a need to splice (elongate) plywood sheets forming walls arises, as according to the existing assortment the length of the plywood sheet doesn't exceed $2440 \mathrm{~mm}$.

The process of plywood splicing is very time-consuming, it requires the use of specialized equipment, and the reliability of joints doesn't always meet required characteristics [2]. To make production techniques easier it has been offered to eliminate plywood sheet splicing, assembling a section from wall fragments, leaving clearances between them. The clearance between them can be minimal (firm contact of wall fragments) or it can have a certain value, due to which they will exert increasing influence on beam strength.

Proposed structural unit can consist of one or several plywood walls, placed at a certain distance from one another. Wooden bars are glued on the top edges of these walls, forming

\footnotetext{
*Corresponding author: natalia.mag.pyo@gmail.com
} 
section flanges. Flanges of adjacent walls are glued together, forming rigid structure which prevents twisting. Along the whole length plywood walls are broken with clearances without longitudinal splicing of sheets. Proposed structural unit is highly technological due to the elimination of plywood wall splicing.

In order to prepare the structural model we have made an analysis of used beam structures made from standard materials. Steel beams with perforated walls made from rolled section with walls cut in curved line are widely used. Two halves of cut beam are connected together by means of wall extrusions welding. As a result the section height, moment of inertia and resistance moment increase, which leads to the increase of load capacity for $20-30 \%$.

Openings in the beam walls change the picture of stress state: at the edges near openings normal-stress diagrams become nonlinear even in the elastic stage of material behavior because of stress concentration development.

Reinforced concrete beams with perforated walls are calculated as statically indeterminate systems. Members of chords and supports are considered as nonaxially loaded ones taking into account concrete plastic properties; properties of cross section are calculated with account of weakening (in net structural area). Stress concentration in perforated zones is compensated by constructional reinforcement [3-5].

Open-frame reinforced-concrete girders are considered as redundant framework. They are calculated either using computers as frameworks with rigid bar connections, either by rough method based on decomposition of main girder system by false knuckles [6-7].

Wooden beams with composite section and keyed and dowel joints are used in covers structure. Furthermore it is generally thought that connecting elements are designed not only to take the shearing force; stress concentration in connecting elements locations is not taken into account.

Thus, we can highlight the following assumptions of behavior of beam structure with perforated walls: simplified design model excluding non-linearity of stress distribution across the section; design model including stress concentration induced by perforation holes; open-frame girder.

\section{Parameter determination of stress-strain behavior of perforated beams using photoelasticity method}

Photoelastic stress research method (photoelastic analysis) was used for determination of beams behavior and impact of perforated holes on stress distribution because it was most illustrative method of experimental research.

Photoelastic analysis is based on physical phenomena of optical polarization, double refraction, interference effect and make a connection between optical effect and power characteristics of loaded transparent model [8-10].

For tests we have made beam mockups of the same size: one beam without perforated holes and three beams with perforated holes (different perforation pitch and holes size) (fig. 1.) 


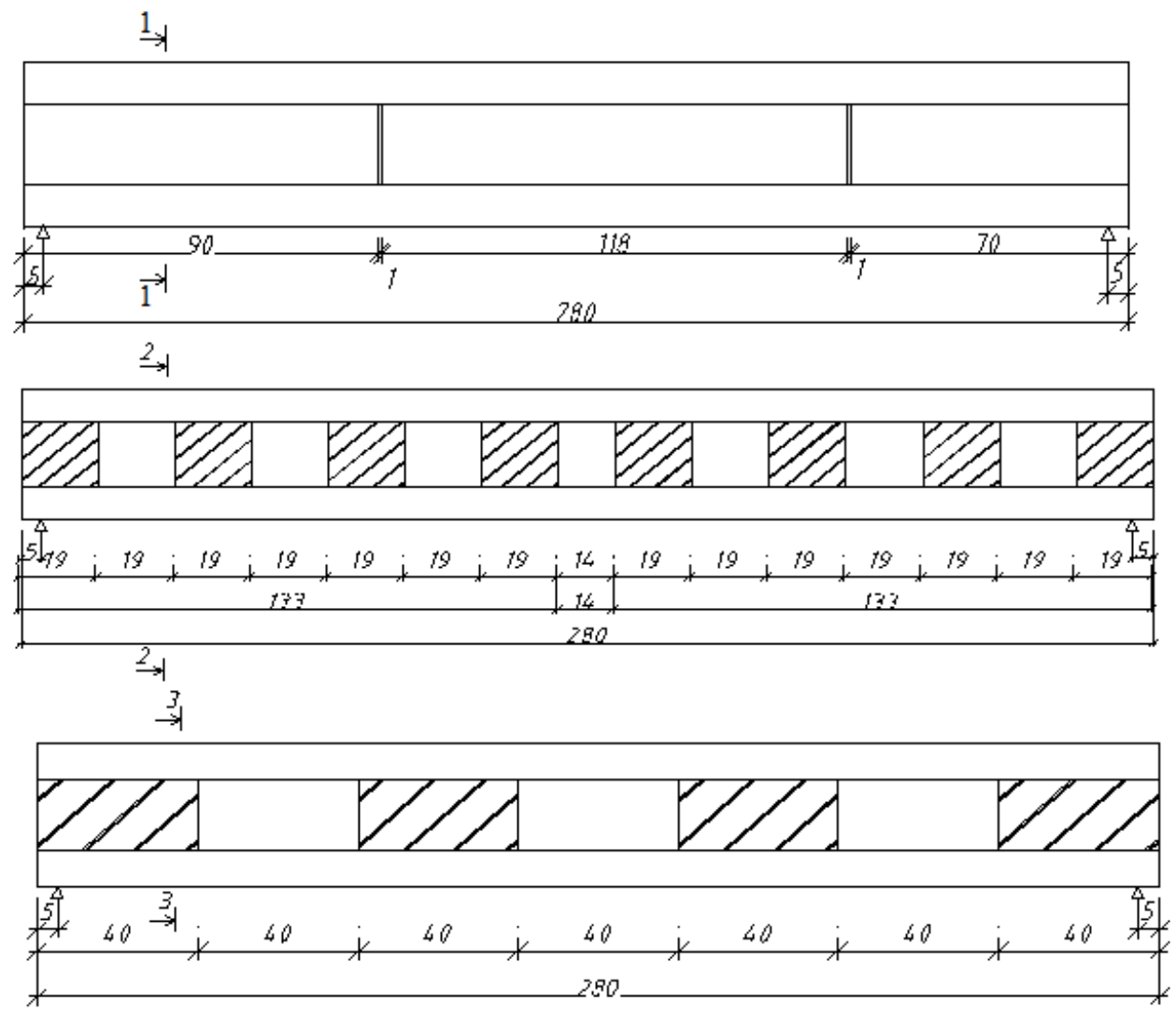

Fig. 1. Scheme of experimental beams with perforated walls made from epoxymal

Mockups are made of epoxymal on the basis of epoxy resin ED-20, hardened with maleic anhydride. Epoxymal perfectly suits for experiments: it is characterized by high optical sensibility, doesn't have edge effect and is easily processed. Beams mockups were put in the field of aligned polariscope (fig. 2) and were loaded with concentrated loads in the middle of span and at distances of third and fourth of span from supports.

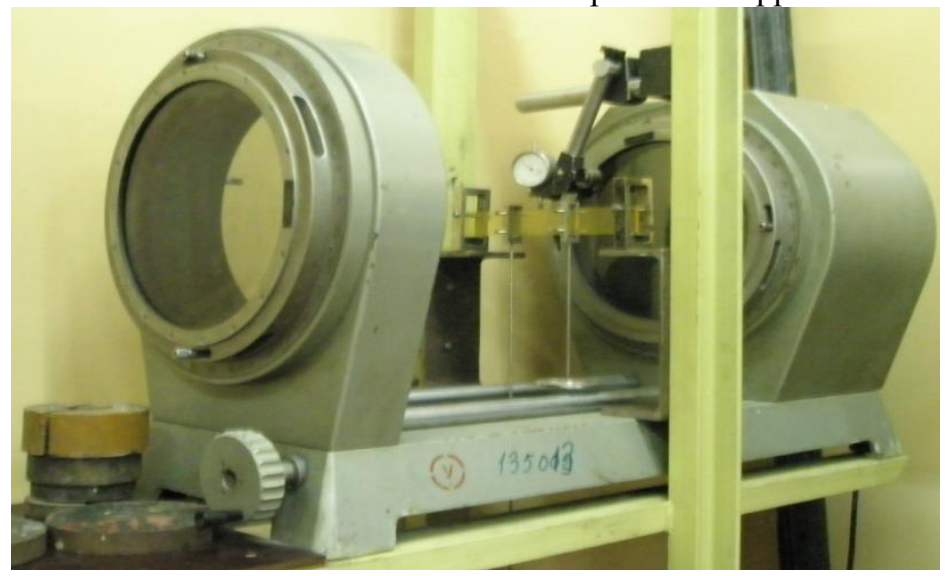

Fig 2. Polariscope with beam model loaded in the middle of span

Beams are loaded in steps with fixation of deformation value at each step. 


\section{Results}

Based on test results the relation between amounts of load applied and appropriate deformations for each beam and loading pattern has been prepared (table 1). For deformation measurement we used the dial gauge with scale interval of $0.01 \mathrm{~mm}$.

Table 1. Comparison of observed and theoretical deformation values

\begin{tabular}{|l|c|c|c|c|c|}
\hline \multirow{2}{*}{ Deformation value, mm } & \multicolumn{5}{|c|}{ Design load, N } \\
\cline { 2 - 6 } & $\mathbf{6 3}$ & $\mathbf{1 4 3}$ & $\mathbf{1 8 3}$ & $\mathbf{2 4 7}$ & $\mathbf{2 8 7}$ \\
\hline & Observed results: \\
\hline $\begin{array}{l}\text { Beam without perforated } \\
\text { holes (full section) }\end{array}$ & 0.26 & 0.56 & 0.71 & 0.99 & 1.19 \\
\hline $\begin{array}{l}\text { Beam with perforation value } \\
\text { of 1 mm }\end{array}$ & 0.27 & 0.59 & 0.79 & 1.06 & 1.24 \\
\hline $\begin{array}{l}\text { Beam with perforation value } \\
14 \mathrm{~mm}\end{array}$ & 0.35 & 0.81 & 1.03 & 1.44 & 1.66 \\
\hline $\begin{array}{l}\text { Beam with perforation value } \\
40 \mathrm{~mm}\end{array}$ & 0.39 & 0.88 & 1.16 & 1.63 & 1.87 \\
\hline \multicolumn{7}{|c|}{ Theoretical values: } \\
\hline Weak section & 0.3042 & 0.6906 & 0.8837 & 1.1928 & 1.386 \\
\hline Full section & 0.2659 & 0.6036 & 0.7725 & 1.0427 & 1.2116 \\
\hline
\end{tabular}

Besides we have made photofixation of interference patterns due to which it can be inferred about the condition of mockeups stress-strain. Examples of interference patterns of tested beam without perforated wall and with different load patterns are presented in fig. 3 .

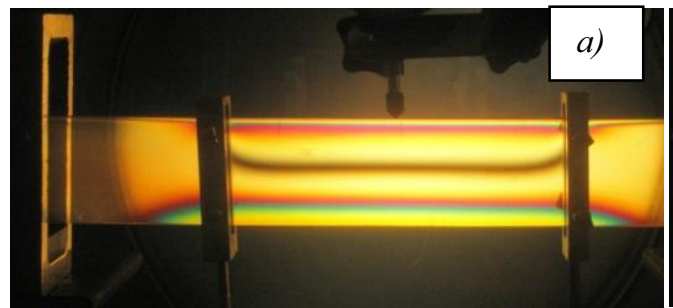

a) loading at 1/4 of span

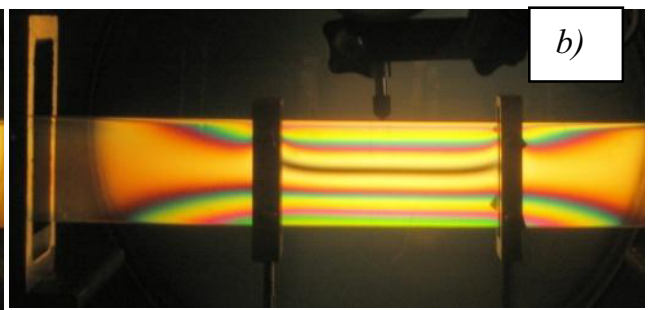

b) loading at 1/3 of span

Fig 3. Interference pattern with pure bending of beam mockup

\section{Conclusions}

As a result of work performed we can make following conclusions:

1. At the bottom of calculation of beam elements different assumptions about the behavior of these structures are used.

2. Information about comparative stress condition of glued plywood beams with different sizes of clearances can be obtained from photoelastic analysis. It will allow to see continuous stress pattern illuminated by polarized light in the mockup of interest and choose the best possible clearance size, because the photoelastic analysis is the most illustrative experimental technique for study of stress-strain behavior of solid bodies.

3. Comparison of interference patterns in beam mockups and their analysis show that perforation holes have a slight impact on stress values, which allows applying easy for 
manufacture and economic beams with perforated walls for construction of low-rise buildings cover.

\section{References}

1. G.N. Zubarev, F.A. Boitemirov, Structures from wood and plastic (2008)

2. G.G. Karlsen, U.V. Slitskouhova. Structures from wood and plastic (1996)

3. V.G. Permyakov, A.A. Bykov, A.U. Zobacheva, A.A. Balakirev, A.V. Kalugin. Newsletter of Perm National Research Polytechnic University. Construction and architecture, 1, 32-39 (2010)

4. A.D. Rakhmanov. Contemporary issues of science and education, 6, 183 (2013)

5. R.A. Yarkin, V.M. Strulev. Newsletter of Tambov State Technical University, 9, 486$492(2003)$

6. F.S. Zamaliev. Newsletter of MSUCE, 12, 53-60 (2012).

7. A.K. Yagofarov, K.K. Yagofarov, Newsletter of Ural State University of Railway Transport, 1, 57-77 (2016)

8. A.Y. Alexandrov, M.K. Akhmetzyanov. Photoelastic techniques of deformable body mechanics, (1993)

9. A.S. Koshelenko, G.G. Pozdnyak. Theoretical basis and practice of photomechanics in mechanical engineering, (2004)

10. G.L. Khesin. Photoelastic analysis. 1, 2, 3, (1995). 